\title{
A recente produção científica sobre currículo e multiculturalismo no Brasil (1995-2000): avanços, desafios e tensões*
}

\author{
Antônio Flávio Barbosa Moreira
}

Universidade Federal do Rio de Janeiro, Faculdade de Educação

\section{Introduzindo o estudo}

Vive-se hoje em um mundo marcado pelas nefastas consequiências de um processo de globalização excludente, resultado não de uma fatalidade econômica, mas de uma política consciente e proposital que busca liberar os determinismos econômicos de todo controle e submeter governos e cidadãos às forças assim liberadas. Esse processo constitui, como afirma Bourdieu (2001):

[...] a máscara justificadora de uma política que visa universalizar os interesses e a tradição particulares das potências econômicas e politicamente dominantes, sobretudo

* Trabalho derivado da pesquisa $O$ multiculturalismo $e$ o campo do currículo no Brasil, coordenada por Antônio Flávio Barbosa Moreira e Elizabeth Fernandes de Macedo (UERJ) e realizado com apoio do CNPq. Texto apresentado na sessão especial "Multiculturalismo: desafios para a educação", na 24 Reunião Anual da ANPEd, realizado em Caxambu-MG, de 7 a 11 de outubro de 2001. os Estados Unidos, e estender ao conjunto do mundo o modelo econômico e cultural mais favorável a essas potências, apresentando-o ao mesmo tempo como norma, um tem-queser e um fatalismo, destino universal, de modo a obter adesão ou, pelo menos resignação universais. (p. 90)

Entre as consequiências imediatamente visíveis da globalização podem-se mencionar: o aumento das desigualdades econômicas entre os países e no interior de cada um deles, o desemprego crescente, o desaparecimento progressivo de universos autônomos de produção cultural pela imposição de valores comerciais, assim como a destruição das instâncias coletivas capazes de fazer frente aos efeitos do que Bourdieu (1998) denomina de máquina infernal. Os atos terroristas nos Estados Unidos, em 11 de setembro de 2001, mostraram os conflitos que essa máquina pode causar e tornaram claro que, em tempos de crise, o neoliberalismo parece não ter soluções a oferecer. As trágicas imagens de Nova York e Washington expuseram com nitidez a vulnerabilidade dos Estados Unidos, bem como, pode-se deduzir, de outros países e grupos favorecidos pelo processo de globalização em curso. 
Além de provocarem desastrosos efeitos na economia mundial e de intensificarem o arbítrio, a perseguição, o racismo e a xenofobia, os acontecimentos de setembro levaram países do Primeiro Mundo a se articularem para evitar novos atentados, garantir a segurança no mundo ocidental e preservar os atuais arranjos sociais e econômicos. Entretanto, represálias e outras medidas, mais ou menos violentas, que venham a ser tomadas, serão muito pouco eficazes se, como bem afirmou Beck (2001), não forem levadas em conta, com muito mais seriedade, a dignidade humana, a identidade cultural e a diferença. Para este autor, há que se atentar para as desigualdades econômicas e se distribuir os frutos da globalização com mais justiça. Há também que se reconhecer a pluralidade cultural que cada vez mais se expressa no mundo de riscos globais em que vivemos, tanto nos setores beneficiados pela globalização como nos que ela tem ajudado a marginalizar.

Nossas sociedades contemporâneas são inegavelmente multiculturais. Nelas, as diferenças derivadas de dinâmicas sociais como classe social, gênero, etnia, orientação sexual, cultura e religião expressam-se nas distintas esferas sociais. O termo multiculturalismo, todavia, pode indicar diversas ênfases: a) atitude a ser desenvolvida em relação à pluralidade cultural; b) meta a ser alcançada em um determinado espaço social; c) estratégia política referente ao reconhecimento da pluralidade cultural; d) corpo teórico de conhecimentos que buscam entender a realidade cultural contemporânea; e) caráter atual das sociedades ocidentais (Canen e Moreira, 2001). É essa última perspectiva, adotada por Kincheloe e Steinberg (1997), que vejo como mais apropriada para expressar os complexos fenômenos culturais contemporâneos. Multiculturalismo representa, em última análise, uma condição inescapável do mundo ocidental, à qual se pode responder de diferentes formas, mas não se pode ignorar. Multiculturalismo refere-se à natureza dessa resposta. Educação multicultural, conseqüentemente, refere-se à resposta que se dá, a essa condição, em ambientes educacionais.

Pode-se promover a educação multicultural para desenvolver sensibilidade para a pluralidade de valo- res e universos culturais, decorrente do maior intercâmbio cultural no interior de cada sociedade e entre diferentes sociedades. Pode-se também empregá-la para resgatar valores culturais ameaçados, visando-se garantir a pluralidade cultural. Pode-se, ainda, buscar reduzir os preconceitos e as discriminações (Canen, 1998). Pode-se, com o auxílio da educação multicultural, destacar a responsabilidade de todos no esforço por tornar o mundo menos opressivo e injusto. Como acentuou Beck (2001, p.4), não sem certo tom de cinismo, "ajudar os que foram excluídos não é mais uma tarefa humanitária. É do próprio interesse do Ocidente: a chave de sua segurança". Com o apoio da educação multicultural pode-se, por fim, propiciar a contextualização e a compreensão do processo de construção das diferenças e das desigualdades, enfatizandose que elas não são naturais e que, portanto, resistências são possíveis.

A educação multicultural pode também ser usada, em outro enfoque, para integrar grupos que contestem valores e práticas dominantes, celebrar manifestações culturais dominantes, garantir a homogeneidade e tentar apagar (ou esmaecer) as diferenças, bem como evitar que a compreensão da constituição das diferenças questione hierarquias estabelecidas.

A decisão relativa à resposta a ser dada demanda a explicitação do que está sendo chamado de diferença. Com base em McCarthy (1998), concebo diferença como o conjunto de princípios organizadores de seleção, inclusão e exclusão que informam o modo como mulheres e homens marginalizados são posicionados e constituídos em teorias sociais dominantes, políticas sociais e agendas políticas. No âmbito da diferença incluem-se, então, os atos que têm classificado e oprimido indivíduos e grupos, desautorizando e silenciando suas vozes e histórias.

Diferença refere-se, portanto, mais à distribuição desigual de pessoas na organização social, decorrente de aspectos que "centralmente" as distinguem, do que à idéia de grupos e indivíduos distintos partilhando aspectos comuns a uma única raça - a humana. Nessa perspectiva, a produção da diferença é um processo 
social, não algo natural ou inevitável. A diferença pode e deve ser desafiada, em movimento que vise promover a aceitação do imperativo transcultural proposto por Boaventura de Sousa Santos (1997): as pessoas têm direito a ser iguais sempre que a diferença as tornar inferiores; contudo, têm também direito a ser diferentes sempre que a igualdade colocar em risco suas identidades.

Considerando-se a inevitável presença da diferença em nossa sociedade e em nossas escolas, cabe perguntar: como se tem lidado, nas salas de aula, com a diferença cultural? Como se tem buscado compreender o processo de construção dessas diferenças? Que resposta vem sendo dada ao caráter multicultural de nossa sociedade? Que propostas vêm sendo elaboradas para enfrentar os desafios decorrentes dessa condição? Como se tem procurado tornar os currículos multiculturalmente orientados? Como os pesquisadores do campo do currículo têm incorporado, em seus estudos, a preocupação com o multiculturalismo? Como se têm beneficiado do diálogo com grupos que vêm realizando importantes experiências de educação multicultural, principalmente na educação indígena e na educação de jovens e crianças negras?

Conforme acentuam com propriedade Gonçalves e Silva (1998, p. 99), "não há educação multicultural separada do contexto de luta, dos grupos culturalmente dominados, que buscam modificar, por meio de suas ações, a lógica pela qual a sociedade produz sentido e significados de si mesma”. Alguns desses grupos têm desenvolvido, em espaços formais e não-formais, projetos educativos, com o objetivo de tornar mais visíveis e audíveis os rostos e as vozes que têm sido marginalizadas e silenciadas na sociedade e na escola (Pinto, 1999). Nesse esforço, têm acumulado conhecimentos que podem oferecer valiosos subsídios para a adoção de uma postura multicultural nas escolas e salas de aula dos sistemas formais de ensino. Têm mesmo chegado a afetar propostas curriculares oficiais e conseguido formalizar, na legislação, alguns dos espaços conquistados na prática social, garantindo, então, ao menos na esfera legal, o direito à diferença cultural (Cury, 1999).
Mas, assim como não há educação multicultural apartada das lutas e das conquistas dos movimentos sociais, também não há educação multicultural sem uma produção acadêmica significativa que sustente os projetos desenvolvidos nos sistemas de ensino (Gonçalves e Silva, 1998). Daí a importância de se entenderem os rumos dessa produção em nosso país. No presente trabalho, procurei caminhar nessa direção. Meu objetivo foi compreender como, em estudos recentes, que focalizam teorias, práticas e propostas pedagógicas e curriculares, se evidencia a preocupação com o multiculturalismo. Busquei identificar, nesses estudos, as temáticas tratadas, os principais argumentos, as influências teóricas mais significativas, os enfoques metodológicos, as contribuições e as lacunas. A análise efetuada suscitou-me reflexões sobre algumas tensões que parecem perpassar o processo de construção de currículos multiculturalmente orientados. Acompanhame, ao longo do texto, o ponto de vista de que é conveniente e possível conferir aos currículos de nossas escolas uma perspectiva multicultural.

Considerando que tanto Gonçalves e Silva (1998) como Canen, Arbache e Franco (2000) examinaram dissertações e teses que estudaram a educação multicultural, centrei minha atenção em artigos publicados em periódicos brasileiros ${ }^{1}$ e em trabalhos apresentados nas reuniões da Associação Nacional de Pesquisa e Pós-Graduação em Educação (ANPEd), fundamentalmente de 1995 até o ano 2000. ${ }^{2}$ Analisei um total de

${ }^{1}$ Os periódicos analisados foram: Cadernos de Pesquisa, Revista Brasileira de Educação, Educação \& Realidade, Educação e Sociedade, Educação em Revista. Foram escolhidos por terem sido os únicos periódicos brasileiros classificados como internacionais na Avaliação dos Periódicos Brasileiros de Educação, promovida em 2001, envolvendo a Associação Brasileira de Tecnologia Educacional (ABT), a Associação Nacional de Pesquisa e Pós-Graduação em Educação (ANPEd), o Instituto Nacional de Estudos e Pesquisas Educacionais (INEP) e a Coordenação de Aperfeiçoamento de Pessoal de Nível Superior (CAPES).

${ }^{2}$ Foram também consultados, para definição dos artigos a serem analisados, além dos periódicos em pauta e dos Anais das Reuniões da ANPEd, os volumes I, II e III do Banco de Dados. 
46 textos, todos elaborados por pesquisadores brasileiros. Selecionei-os por relacionarem explicitamente multiculturalismo, escola e currículo ou por abordarem a expressão de diferenças referentes a classe social, etnia, gênero, orientação sexual e cultura em instituições escolares e arranjos curriculares. ${ }^{3}$ Minha preocupação com a intersecção multiculturalismo-currículo decorre da importância que atribuo ao currículo: vejo-o como instrumento privilegiado por meio do qual propostas e práticas multiculturalmente orientadas vêm sendo e podem ser implementadas no país, tanto no sistema formal de ensino como em projetos que correm em paralelo ao sistema oficial. Concebo currículo como todas as experiências organizadas pela escola que se desdobram em torno do conhecimento escolar. Incluo no âmbito do currículo, assim, tanto os planos com base nos quais a escola se organiza, como a materialização desses planos nas experiências e relações vividas por professores e alunos no processo de ensinar e aprender conhecimentos. Nessa perspectiva, o professor encontra-se necessariamente comprometido com o planejamento e com o desenvolvimento do currículo.

Minha preocupação com a escola decorre de considerá-la capaz de promover a crítica do existente e o questionamento do que parece inscrito na natureza das coisas; capaz, então, de formar indivíduos não conformistas, rebeldes, transgressores, comprometidos com a luta contra toda e qualquer opressão. Decorre de considerá-la, em síntese, espaço público em que, em meio a práticas, relações sociais e embates, se produzem significados e identidades. Nesse espaço, novos tempos podem ser anunciados.

O interesse pelo processo curricular desenvolvido em nossas escolas e salas de aula encontra-se, em

organizado pelo Grupo de Estudos sobre Cotidiano, Educação e Cultura(s), da PUC-Rio, coordenado por Vera Candau $(1997,1999,2001)$.

${ }^{3}$ Não pretendi, com esse recorte, desvalorizar outras modalidades de diferença que poderiam ter sido incluídas. Corri, em decorrência, os riscos inerentes a qualquer recorte. maior ou menor grau, em todos os artigos analisados, mesmo nos que examinam ações desenvolvidas no âmbito dos movimentos sociais. É esse interesse que me esforço, a seguir, por entender.

\section{As temáticas dos artigos: ênfases, lacunas e contribuições}

Ciente das dificuldades envolvidas em qualquer categorização, bem como das superposições que inevitavelmente ocorrem, procurei verificar as temáticas predominantes nos 46 textos analisados. ${ }^{4}$ Identifiquei as seguintes: currículo e etnia (18); currículo e diversidade cultural (14); multiculturalismo e propostas curriculares oficiais (4); multiculturalismo e formação docente (4); currículo e gênero (3); currículo, gênero e etnia (1); currículo e homossexualidade (1); currículo e classe social (1).

\section{Currículo e etnia}

Foram incluídos nessa temática, claramente dominante, seis artigos que abordam a educação de crianças, jovens e adultos negros (Candau e Anhora, 2000; Gomes, 1996; Santana, 2000; Santos, 1997; Silva, A.C., 1999; Souza, 1997); cinco sobre educação indígena (Campos, 2000; Côrtes, 1996; Gomes, A. M. R., 2000; Monte, 2000; Silva, R. H. D., 1999); dois sobre a educação de ciganos (Ferreira, 1998; Gomes, 1999); um enfocando as discussões sobre racismo em cursos de formação de professores (Paraíso, 1997); um tratando da política de ingresso de minorias raciais na universidade americana (e as influências nos cursos e currículos) (Oliven, 1996); um defendendo o combate

${ }^{4}$ Para definir a categorização utilizada no texto, inspirei-me nas categorizações dos Bancos de Dados do Grupo de Estudos sobre Cotidiano, Educação e Cultura(s) (Candau, 1997, 1999, 2001), na categorização elaborada por Gonçalves e Silva (1998), nas dinâmicas sociais usualmente incluídas no âmbito do multiculturalismo (Kincheloe e Steinberg, 1997), bem como nos artigos examinados. 
ao racismo desde a pré-escola (Valente, 1995); um examinando o papel da educação na constituição de diferenças étnicas (Valente, 1998) e um referindo-se ao racismo de modo mais amplo e ressaltando a importância das histórias de vida na construção de uma escola mais humana e mais intercultural (Kramer, 1995).

Nos artigos que privilegiam a educação do povo negro, encontram-se acentuados: as opressões vividas pelas crianças e pelos adolescentes negros na escola, as dificuldades envolvidas no tratamento do problema racial nas salas de aula (o mito da democracia racial chega a ser evocado para justificar a despreocupação com a questão), o despreparo dos professores, a falta de material didático adequado, as representações estereotipadas dos negros nos livros-texto e, em alguns poucos casos, a importância de se incluírem nos currículos estudos da história e da cultura da população negra. Comum a todos os artigos parece ser a perspectiva de transformar as escolas em espaços públicos que melhor atendam às necessidades e aos interesses de inúmeros alunos que têm sido objeto de preconceitos e discriminações. Subjaz a alguns textos, porém, o ponto de vista de que as esperanças na mudança se depositam mais em ações dos movimentos sociais e em projetos de intervenção do que em reformas curriculares.

Nos trabalhos sobre educação indígena, propõese, dominantemente, uma escola diferenciada, com professores indígenas, que supere o integracionismo e propicie o bilingüismo cultural. Focaliza-se, também, a situação de Minas Gerais, em que escolas indígenas integram a rede estadual de ensino e professores indígenas são contratados pelo Estado. Nos estudos sobre ciganos argumenta-se a favor de escolas em que convivam ciganos e não-ciganos (a despeito das dificuldades de relacionamento), com professores não ciganos, e nas quais as crianças ciganas se sintam consideradas e venham a aprender outros conhecimentos e outras manifestações culturais, sem que se aculturem totalmente. A discussão ainda carece, a meu ver, de aprofundamento. Em que casos será mais democrática e mais efetiva a inclusão de crianças de diferentes grupos sociais nas redes escolares oficiais?
Quais têm sido os resultados dessa inclusão? Em que casos devemos estimular escolas diferenciadas? Como têm funcionado as escolas já criadas? Em que medida esse funcionamento as recomenda?

\section{Currículo e diversidade cultural}

Nesta categoria foram reunidos dez trabalhos que discutem, com diferentes graus de ênfase em situações práticas ou em reflexões teóricas, questões referentes à concepção de multiculturalismo, à diversidade cultural, à diferença cultural, à desigualdade socioeconômica, à identidade cultural, às culturas na escola e, ainda, à tensão universalismo versus relativismo (Canen, Arbache e Franco, 2000; Coutinho, 1997; Cury, 1999; Dayrell, 1996; Franco, 1999; Gomes, 1997; Kreutz, 1999; Oliveira, Canen e Franco, 2000; Silveira, 1999; Valente, 1996). Foram também incluídos quatro estudos que enfocam as condições educacionais de alguns grupos de imigrantes (Demartini, 2000; Kreutz, 2000; Meyer, 2000; Weller, 1995).

No que se refere à concepção de multiculturalismo adotada, é dominante a opção por um multiculturalismo crítico, ${ }^{5}$ nem sempre claramente definido. Em apenas um artigo evidenciou-se uma postura bastante liberal (e ingênua) (Coutinho,1997), com base na qual se defendem a valorização das diversas culturas, a convivência pacífica entre os indivíduos e a difusão dos valores humanos universais (verdade, amor e paz).

${ }^{5}$ Para Tomaz Tadeu da Silva (1999), o multiculturalismo crítico caracteriza-se por não conceber as diferenças culturais separadamente de relações de poder. Enquanto em uma perspectiva liberal apela-se para o respeito à diferença, por se considerar que sob a aparente diferença há uma mesma humanidade, no multiculturalismo crítico a própria definição do que é humano é vista como resultado de relações de poder. Ainda segundo o autor, a perspectiva crítica do multiculturalismo pode ser dividida em uma concepção pós-estruturalista (que concebe a diferença como essencialmente um processo lingüístico e discursivo) e uma concepção mais materialista (para a qual os processos institucionais, econômicos, estruturais, estariam na base da produção dos processos de discriminação e desigualdade baseados na diferença cultural). 
Entre os temas abordados nos artigos, podem-se mencionar: o caráter homogeneizador da escola (justificado por meio de um "discurso da igualdade" que acaba por provocar exclusões e reforçar desigualdades), os desafios postos à escola pela diversidade cultural contemporânea, a participação do movimento docente na criação de uma escola aberta à diversidade cultural, a necessidade de se avançar nas questões teóricas e práticas envolvidas na formação de identidades multiculturalmente comprometidas, a urgência em se trabalharem as lacunas entre a cultura da escola e a cultura de origem dos alunos, a importância de se confrontarem as representações culturais que circulam na escola e que circulam em outros espaços de produção cultural. Explicitam-se, em quase todos os estudos, a rejeição ao ainda costumeiro caráter etnocêntrico das práticas curriculares, assim como a preocupação com o processo de produção de identidades nos ambientes escolares. A intenção parece ser, como sugere Kreutz (1999), promover na escola o encontro entre diferentes formas de ser, pensar, sentir, valorizar e viver, construídas em um marco de tempo e de espaço que dão pertinência e identidade aos indivíduos e aos grupos sociais.

Entre os artigos que abordam situações de imigrantes, encontra-se um relato do trabalho pedagógico desenvolvido para melhorar a integração do imigrante na sociedade alemã (Weller, 1995). Encontram-se também trabalhos que explicitam as contradições envolvidas nas tentativas de grupos imigrantes no Brasil de empregarem suas escolas para preservar manifestações culturais de origem.

\section{Multiculturalismo e propostas curriculares oficiais}

Este grupo englobou os estudos que analisam como, em propostas curriculares oficiais, questões referentes ao multiculturalismo são ou devem ser tratadas. Dois focos foram identificados: os Parâmetros Curriculares Nacionais (em três artigos) ${ }^{6}$ e a sugestão

${ }^{6}$ Canen (1998), Lopes (1997), Maranhão (2000). Tais estudos enfocam o documento introdutório dos PCN e o documento referente ao tema transversal pluralidade cultural. de um núcleo curricular básico, constituído por conceitos nucleares, no qual se incorpore a tensão tradição cultural da humanidade versus pluralismo cultural (em um artigo) (Bonamino e Brandão, 1995). Os textos sobre os PCN propõem-se a identificar a perspectiva multicultural adotada. Enfatiza-se que, segundo os PCN, a diversidade cultural poderia estabelecerse em contexto não plural, pautada, fundamentalmente, no consenso. Argumenta-se, também, que o documento não problematiza a idéia de identidade nacional, desconsiderando tanto o processo socioistórico de constituição de uma imagem nacional, como o processo de construção de uma sociedade marcada pela desigualdade socioeconômica.

São muito pouco freqüentes as referências ao caráter multicultural de propostas curriculares dos diferentes estados e municípios do país. Senti também falta de estudos que investigassem se e como, em escolas e salas de aula, o caráter multicultural de propostas oficiais estaria sendo interpretado e preservado.

\section{Multiculturalismo e formação docente}

Os quatro textos incluídos nessa categoria focalizam a formação do professor multiculturalmente orientado (Canen,1997, 1999; Gomes, N. L., 2000; Pinto, 1999). Defende-se a formação de um professor reflexivo multiculturalmente competente. Sugerem-se, também, caminhos para a formação pretendida: inclusão de disciplinas especificamente voltadas para a educação multicultural; novos conteúdos, procedimentos e valores no âmbito das disciplinas pedagógicas existentes; contato dos futuros docentes com diferentes realidades culturais. Destacam-se, ainda, a necessidade de discussões sobre o papel da escola e a análise de experiências multiculturais bem sucedidas, inclusive das que ocorrem paralelamente ao sistema oficial. Por fim, lastima-se a ausência de materiais didáticos que facilitem o trabalho dos que formam novos professores.

A necessidade de professores bem preparados para enfrentar os desafios provocados pela pluralidade cultural da sociedade e das escolas, como já afirmei, é realçada em muitos artigos. No entanto, são pouco 
numerosos, no conjunto examinado, os estudos que procuram verificar se e como os currículos dos cursos de formação docente evidenciam uma orientação multicultural. Trata-se, penso, de lacuna a ser preenchida.

\section{Currículo e gênero}

As escassas investigações sobre currículo e gênero focalizam os silêncios, os preconceitos e as discriminações referentes a gênero, que se encontram no currículo, tanto no currículo formal como no currículo em ação (Carvalho e Vianna, 1999; Paraíso, 1995; Souza, 1999). Realça-se a importância da escola na aprendizagem de identidades masculinas e femininas. Discute-se, também, como a majoritária presença de mulheres no magistério é tornada invisível na pesquisa educacional, no universo escolar e na formação de professores em nível de segundo grau.

A despeito das inegáveis conquistas dos movimentos de mulheres no processo de desafiar as relações patriarcais na sociedade brasileira, vencendo resistências seculares, os efeitos dessas lutas na elaboração de propostas curriculares multiculturalmente orientadas não são muito evidentes nos artigos analisados.

\section{Currículo, gênero e etnia}

O único texto incluído neste grupo procura entender como as interseções das dinâmicas sociais gênero e etnia se refletem no currículo em ação na formação docente (Paraíso, 1998). Afirma que gênero e etnia constituem campos de silêncio nas salas de aula, o que dificilmente pode contribuir para que se reduzam, na sociedade, o etnocentrismo, a homofobia e o sexismo.

Sugiro que se desenvolvam estudos que focalizem a operação simultânea de diferentes dinâmicas sociais (classe social, raça, gênero, orientação sexual etc.), cujas relações nos distintos espaços sociais, como argumenta McCarthy (1988), são sistematicamente contraditórias ou "não sincrônicas". Segundo o autor, o conceito de "não sincronia" pode ser útil para se compreender que "os indivíduos e grupos, em suas relações com instituições econômicas, políticas e cultu- rais como as escolas não compartilham uma mesma consciência nem expressam os mesmos interesses, necessidades ou desejos em um dado momento" (p. 275). Indico, assim, o emprego da expressão "não sincronia" para melhor se entender a complexidade inerente aos cruzamentos de diferentes dinâmicas na formação de identidades individuais ou grupais descentradas e híbridas. Por simplificar o que de fato ocorre, cabe rejeitar na análise qualquer lógica segundo a qual os movimentos caminham em paralelo ou as opressões se adicionam umas às outras.

\section{Currículo e homossexualidade}

O único estudo sobre currículo e homossexualidade focaliza o tratamento dispensado por professores de educação física ao aluno homossexual (Cunha Jr., 1996). Para uns, esse aluno é visto como frágil ou incapaz de realizar determinados exercícios. Outros omitem-se em relação à questão, não contribuindo, então, para evitar atitudes discriminatórias. $\mathrm{O}$ estudo recomenda que a escola dê visibilidade ao assunto, reconheça sua importância e proponha ações objetivas para abordá-lo.

A despeito do significativo número de pesquisas que vêm sendo realizadas, principalmente em países anglo-saxônicos, sobre a temática (gay studies), podese afirmar que seu desenvolvimento no Brasil, no âmbito do currículo e do multiculturalismo, é ainda bastante limitado.

\section{Currículo e classe social}

Foi incluído nesta categoria o artigo que aborda a construção do projeto político-pedagógico em uma escola para crianças das camadas populares (Hage, 1996). Apoiado na teoria crítica, o estudo sustenta que uma escola que atende aos interesses dessas camadas deve comprometer-se com uma prática educativa transformadora e emancipatória. Para que isso ocorra, precisa favorecer o diálogo, a empatia e o respeito ao outro, desenvolvendo uma gestão democrática. Precisa dialogar com outras instâncias da sociedade e com representantes dos movimentos sociais. Precisa consi- 
derar a cultura popular como terreno de possibilidades no qual conflitos e diferenças se explicitam.

Registre-se a secundarização da categoria classe social. Em um país com tantas desigualdades, essa constatação causa, no mínimo, inquietação. Registrese, também, o pouco interesse que o projeto políticopedagógico, chave para a emergência de uma postura multicultural nas escolas, parece estar despertando em nossos pesquisadores.

\section{Complementando a análise das temáticas}

Vale estranhar o fato de poucos autores focalizarem experiências desenvolvidas no âmbito das disciplinas escolares; apenas três o fazem (Cunha Jr., 1996; Franco, 1999; Santos, 1997). Presente em muitas coletâneas estrangeiras, essa é certamente uma área que, mais desenvolvida entre nós, pode estimular experiências voltadas para conferir uma tonalidade multicultural às diferentes disciplinas.

São também ainda parcimoniosas, nos trabalhos em foco, análises dos indispensáveis procedimentos e materiais de apoio a serem empregados nessas experiências. Discussões e sugestões referentes a livros didáticos, estratégias de ensino e práticas de avaliação precisam ser mais desenvolvidas.

Apesar de suas lacunas, as pesquisas a que tive acesso trazem significativas contribuições para novas reflexões e novas práticas no campo do multiculturalismo. Destaco algumas: a necessidade de se desafiarem preconceitos desde a pré-escola; o valor da experiência do pré-vestibular de negros e carentes; a associação da questão didática à perspectiva multicultural; a importância do currículo na promoção de uma educação cultural; a reiteração de que é indispensável articular as experiências curriculares e os projetos dos alunos; o apelo à maior integração escola-família-comunidade nas experiências a serem desenvolvidas; a centralidade da categoria cultura na compreensão do currículo-em-ação; a sempre necessária constatação de que em nossas escolas e em nossas salas de aula persistem relações de poder opressivas que precisam ser enfrentadas; a preocupação com a construção de uma história de práticas pedagógicas multiculturalmente orientadas; a ênfase atribuída às histórias de vida na promoção do respeito ao outro; o reconhecimento de que os significados construídos e compartilhados em espaços culturais que não a escola afetam a formação de identidades sociais.

\section{Abordagens metodológicas}

No conjunto de textos analisados, encontram-se investigações de natureza mais teórica (20): pesquisas bibliográficas, estudos de natureza histórica e análises documentais. Há também estudos que abordam a prática curricular (26). Entendi prática curricular, amparando-me em Gimeno Sacristán (1998), como o conjunto de atividades que os sujeitos envolvidos no processo escolar desenvolvem ao conformarem e materializarem a experiência de ensinar e educar. Entre os estudos da prática predominam as etnografias (combinando análise documental, entrevistas e observações). Poucas focalizam experiências pedagógicas multiculturalmente orientadas. A grande maioria propõe-se a compreender e a denunciar atitudes de preconceito e de discriminação na sala de aula. Os demais estudos da prática privilegiam outros procedimentos: entrevistas, análise documental, questionários, formulação de propostas pedagógicas, relato de experiências.

O enfoque crítico dominante nos estudos da prática, expresso na insatisfação com a realidade e na busca de alternativas, compensa o tom psicologizante, usual em investigações desse tipo. Ou seja, a visão da escola e do currículo como territórios contestados, historicamente construídos, bem como o compromisso com a desestabilização de relações opressivas, acabam preservando o necessário caráter político das discussões. Em vez de uma perspectiva individualista, as análises das práticas curriculares parecem refletir, assim, uma perspectiva pública de compromisso social (Pimenta, 2000).

As estratégias metodológicas geralmente utilizadas na pesquisa qualitativa predominam tanto nos estudos mais teóricos como nos estudos da prática, talvez por se adequarem bem à análise da educação 
multicultural. No entanto, seu emprego não garante, por si só, coerência e rigor. Conforme acentuam Canen, Arbache e Franco (2000, p. 8),

$$
\begin{aligned}
& \text { [...] a pluralidade de estudos qualitativos, que buscam os } \\
& \text { significados que os sujeitos dão à realidade, como constroem } \\
& \text { seus discursos e de que forma desenvolvem suas histórias } \\
& \text { de vida, revelam caminhos fecundos para o pensamento } \\
& \text { multicultural. A coerência entre a perspectiva multicultural } \\
& \text { de valorização da diversidade cultural e desafio a preconcei- } \\
& \text { tos, com estratégias metodológicas, elas mesmas valoriza- } \\
& \text { doras das formas plurais dos sujeitos pensarem e darem sig- } \\
& \text { nificado às suas vidas, é sintomática da emergência e conso- } \\
& \text { lidação dessas formas plurais de fazer pesquisa, em que sujei- } \\
& \text { tos (pesquisadores e pesquisados) interagem, com a riqueza } \\
& \text { de suas visões de mundo, na construção do conhecimento. }
\end{aligned}
$$

Do mesmo modo que na análise de teses e dissertações efetuada por Canen, Arbache e Franco (2000), surpreende a total ausência de pesquisas quantitativas. Tais pesquisas poderiam, como argumentamos as autoras e eu, mapear, nas diferentes regiões do país, aspectos referentes a como identidades culturais e nacionais são tratadas nos respectivos sistemas escolares. Poderiam também permitir que se verificasse como essas identidades estão sendo representadas em propostas curriculares, materiais didáticos e outros artefatos culturais.

Por fim, registro o fato de nenhum estudo analisado derivar de uma pesquisa-ação. Penso que tal tipo de investigação pode mostrar-se particularmente relevante para maior compreensão dos rumos de uma experiência curricular multiculturalmente orientada, certamente marcada por resistências, alianças, negociações, recuos, conquistas, dificuldades e problemas. Pode ser também recomendada para sensibilizar o professor para a diversidade presente na sala de aula. Ademais, pode favorecer ao professor melhor conhecer seu aluno, bem como conceber e desenvolver, competentemente, propostas curriculares adequadas à pluralidade cultural (Stoer e Cortesão, 1999). Incentivo, portanto, a realização e a análise de práticas pedagógicas multiculturalmente informadas pela pesquisa-ação.

\section{Temáticas bibliográficas mais freqüentes}

Inspirando-me em Pimenta (2000), optei por denominar este aspecto de temática bibliográfica e não de bibliografia, por considerar, como ela, mais proveitoso identificar as tendências temáticas em vez dos livros mais citados nas bibliografias.

Uma primeira análise sugeriu-me total dispersão, dada a variedade de autores presentes nas bibliografias. Em um segundo momento, vislumbrei duas grandes linhas. Na primeira integram-se os insights dos saberes construídos a partir dos movimentos sociais e de experiências realizadas fora do sistema escolar, com as contribuições de autores da teoria social e da antropologia. Na segunda linha, mais evidente nos estudos que priorizam o currículo nos sistemas formais de ensino e a formação de professores para esses sistemas, observa-se a influência de teorias e de publicações sobre currículo, formuladas principalmente por autores anglo-saxônicos, franceses e brasileiros, enriquecida por discussões da teoria crítica, dos estudos culturais, dos estudos feministas e do pós-estruturalismo.

Sem pretender examinar de modo detalhado a influência de qualquer autor, permito-me mencionar, com cautela, apenas um nome - Peter McLaren. A despeito do valor e da densidade de sua obra, de seu lúcido posicionamento político, expresso em seu comprometimento com justiça social e emancipação, penso ser preocupante o uso muito freqüente de sua classificação de tendências do multiculturalismo (McLaren, 1997). A verdade é que a realidade poucas vezes se enquadra nas categorizações que buscam torná-la mais facilmente inteligível, às custas de reduções e simplificações exageradas.

Sustento, então, ser necessário que se desenvolvam pesquisas que, de modo mais flexível, procurem melhor entender como nossas teorias, propostas e práticas multiculturais formam-se a partir da mistura de distintos matizes políticos, da integração criativa de variadas orientações, do atrito entre diferentes posturas, do questionamento e da renovação de relações de poder, bem como da inevitável hibridização de saberes, valores, manifestações culturais e identidades. 
Formular textos que nos ajudem a perceber com mais clareza toda a complexidade envolvida no processo de construção das diferenças que nos têm separado e oprimido demanda, fundamentalmente, sensibilidade e abertura, passíveis de se enfraquecerem quando se empregam, de modo rígido, categorizações, classificações e enquadramentos.

\section{Algumas reflexões: tensões e desafios na educação multicultural}

Desenvolvo, nesta parte final, algumas reflexões provocadas pelos artigos analisados. Minha intenção é iluminar temas, ausentes ou presentes nos textos, que constituem tensões e desafios teóricos e/ou práticos a serem enfrentados no âmbito dos esforços por conferir ao currículo e à escola uma orientação multicultural.

Em primeiro lugar, abordo a proposta, presente em alguns artigos (Kreutz, 1999; Valente, 1996, por exemplo), de se substituir o termo multiculturalismo por interculturalismo. Sustenta-se ser necessária uma palavra mais apropriada que multiculturalismo para nomear o processo de criação/significação da diversidade cultural por uma educação igualitária. Afirma-se que o termo multiculturalismo induziria a imaginar uma sociedade construída como um mosaico, formada por culturas diferentes, cada uma delas estática. A expressão interculturalismo, por sua vez, sugeriria uma interrelação dinâmica entre as culturas, com reacomodações e ajustes constantes.

Em outros textos, não incluídos no conjunto dos que analisei, essa discussão também se levanta (Santos e Lopes, 1997, por exemplo). O argumento é similar: o prefixo inter expressa o sentido de interação, troca, reciprocidade e solidariedade entre culturas. Permite também considerar que, ao interagir com outras culturas, uma dada cultura pode se desestabilizar, ser relativizada ou contestada em seus princípios básicos, expondo-se à crítica, o que favorece a eliminação dos seus elementos negativos.

Elizabeth Ellsworth (1999) é outra autora que rejeita o adjetivo multicultural: propõe sua substituição pela palavra multicultura. Para ela, o termo mul- ticultural tem sido usado para qualificar pesquisa e educação. Como adjetivo, submete-se ao que qualifica, está a serviço do que qualifica. Educação multicultural seria, então, um tipo particular de educação. A palavra multicultura aponta para uma inflexão diferente. Designa uma cultura em si e, ao mesmo tempo, permite multiplicar e diversificar a noção de cultura. Resiste a ser usada de modo estático, unitário. Não se subordina a modificar ou fragmentar alguma cultura preexistente. Sugere que cultura é sempre já múltipla, em processo, em construção. Pesquisa e educação são, então, nesse enfoque, multiculturas em processo. $\mathrm{O}$ valor da pesquisa e da prática pedagógica reside na qualidade das multiculturas que os textos e as relações em sala de aula produzem e materializam. Reside nos processos de multicultura que os textos e o ensino apóiam e ampliam.

Proponho algumas questões, com base nos estimulantes posicionamentos apresentados. Não será a concepção de inter/multiculturalismo que adotarmos mais importante que o prefixo a ser empregado? Não será, na verdade, a concepção de cultura que escolhermos que irá conferir ao processo ou um caráter estático ou um caráter dinâmico, produtivo? Não estamos acentuando interações e trocas, tanto no interior das culturas como entre elas, ao concebermos cultura como um conjunto de práticas de significação, que se desenrolam em meio a relações de poder, a conflitos, e que contribuem para formar identidades sociais? Não será a clara expressão de um compromisso político contra toda e qualquer coerção que nos encaminhe a desafiar, no currículo, os preconceitos, os estereótipos e os processos que nos têm categorizado e oprimido - mais importante que a preocupação com o prefixo usado?

Em segundo lugar, enfoco a tensão entre diferença e desigualdade social, mencionada em alguns estudos (Silveira, 1999; Valente, 1996, 1998, por exemplo). Neles, enfatiza-se que a diferença precisa articular-se com desigualdade social. Argumenta-se mesmo que a diferença se configura como problema principalmente em momentos de grande crise econômica, ou seja, em momentos em que as desigualdades 
socioeconômicas se acirram ou correm o risco de se intensificar. Trata-se de discussão sem sombra de dúvida pertinente, particularmente em país como o Brasil, cujas desigualdades, tão visíveis e marcantes que dispensam a apresentação de qualquer evidência, não podem ser ignoradas ou secundarizadas em função da preocupação com a diferença.

Não podemos nos esquecer de que vivemos em uma sociedade capitalista, que deve ser nomeada e compreendida pelo que é. Não há elegância teórica que justifique nosso distanciamento dessa realidade.

Nós nunca devemos justificar como de certo modo necessário ou inevitável o sofrimento que as desigualdades, explorações e alienações [do capitalismo] tanto permitem como freqüentemente produzem. Construímos discursos sobre esses sofrimentos e sobre as políticas institucionais e práticas que os criam, mas seria o cúmulo da arrogância considerar que tais materiais não precisam ser contundentes. [...] a virada lingüística pode estimular-nos a encarar o mundo como um texto, mas algumas pessoas têm mais poder que outras para inscrever suas palavras em nossas vidas e em nossos corpos. (Apple, 1999, p.18, grifo do autor)

Nessa perspectiva, continuam a fazer sentido as preocupações tanto com classe social como com totalidade social. "Só podemos nos esquecer da totalidade se nos interessarmos apenas pela diferença entre os indivíduos, se deixarmos de nos ocupar também da desigualdade entre eles" (García Canclini, 1990, p. 25). Sugiro, portanto, que a preocupação com a desigualdade social se preserve e se aprofunde nos estudos sobre multiculturalismo. Se desigualdades e diferenças encontram-se inextricavelmente associadas na realidade brasileira, é importante que a pesquisa nos auxilie a compreender a complexidade inerente a essa articulação, bem como a formular estratégias de luta.

Ao mesmo tempo, penso ser importante evitar, nas análises, reducionismos que sugiram simples subordinações ao econômico. Se raça e gênero são processos sociais vitais que se conectam a outros processos sociais que operam na educação e na sociedade, não há como considerar que a economia dá conta de todas as relações sociais existentes na sociedade. Não cabe, assim, reduzir o antagonismo racial a uma simples expressão da contradição entre trabalho e capital (McCarthy, 1988). O desafio talvez seja, como argumenta Apple (1999), desenvolver teorias e práticas que incorporem tanto o reconhecimento das diferenças como o compromisso com a redistribuição da riqueza. Trata-se, em síntese, de distinguir entre, por um lado, discursos em que se evidencie a intenção de contribuir para a redução de toda e qualquer opressão e, por outro, discursos que desconsiderem seja a opressão decorrente da diferença cultural, seja a opressão decorrente da desigualdade socioeconômica.

Em terceiro lugar, focalizo a tensão universalismo versus relativismo, pouco explorada nos estudos analisados. Apenas em um artigo (Oliveira, Canen e Franco, 2000) encontra-se um tratamento mais denso da questão, com base no qual se propõe um universalismo ético a posteriori, fundado na racionalidade argumentativa. A meu ver, a discussão merece aprofundamento. Algumas questões precisam ser examinadas cuidadosamente. O que estamos entendendo por identidades, valores, saberes e lógicas universais? Que critérios estamos usando para assim classificá-los? Quem tem o poder de escolher e de aplicar tais critérios? Como articulamos as identidades, valores, saberes e lógicas universais com outras identidades, outros valores, outros saberes e outras lógicas? Como, a partir da perspectiva que assumimos, definimos quem sabe e quem não sabe, o que é racional e o que não é racional, o que é verdadeiro e o que é falso, o que é certo e o que é errado, o que é universal e o que é relativo? Que implicações essas definições têm tido para os currículos e para as práticas desenvolvidas nas escolas? Que seleções, inclusões e exclusões têm sido reforçadas nas escolas? De que modo promover, como sugere Sousa Santos (1997), uma relação equilibrada e instigante entre competência global e legitimidade local? Pode uma visão ressignificada de direitos humanos substituir a visão ocidental de valores e saberes universais? Cabe, como propõe Sousa Santos (1997), considerar como falso o debate universalismo versus relativismo? Como estabelecer um diálogo transcultural que nos leve a uma concepção híbrida de direitos hu- 
manos que, sem recorrer ao universalismo, se organize como constelação de significados locais amplamente inteligíveis?

Essa discussão certamente passa por outra: a possibilidade do diálogo. É viável de fato o diálogo entre os diferentes? É factível um diálogo transcultural? Temos tido sucesso no esforço por compreender o mundo do outro? Ao buscar promover o diálogo não tendemos a adotar uma atitude superior, de quem sabe, de quem pode iluminar "verdades" não percebidas? Conseguimos, nesse esforço, formular estratégias de ação de fato desejadas e aceitas pelo outro? É possível a articulação de diferentes lutas em torno de um projeto comum? Segundo Carlson e Apple (2000), é ingênua a crença desmedida na viabilidade e no potencial do diálogo. As condições para que ele ocorra são desniveladas em nossa sociedade: as vozes autorizadas a circular mais livre e amplamente acabam assumindo posições mais privilegiadas e silenciando as demais. Mostra-se, então, indispensável refletir sobre os fatores que têm impedido o diálogo e sobre os procedimentos que permitam torná-lo mais livre de ameaças e constrangimentos nas escolas e nas salas de aula.

Em quarto lugar, destaco como sempre relevante e atual a reflexão sobre os conhecimentos escolares na educação multicultural. Sempre limitando meu foco à escola, coloco-me contra a visão de multiculturalismo que incentiva eventos episódicos como feiras, exposições, debates, comemorações, nos quais certos aspectos de determinado grupo social são ressaltados. Essas atividades esporádicas podem, no máximo, corresponder a momentos iniciais de um trabalho de sensibilização da comunidade escolar para a diversidade cultural.

Sou, também, contra a estratégia de adicionar ao currículo novas disciplinas que se voltem para o estudo da história e da cultura de alguns grupos culturais ou para a análise de problemas específicos. Se indivíduos e grupos participam de relações opressivas em diferentes instituições políticas, econômicas e culturais, por razões associadas a classe social, etnia, gênero, cultura, religião, orientação sexual, idade, torna-se impossível sobrecarregar o currículo com elementos da história e das experiências de todos esses grupos.

Proponho, em contrapartida, que os conteúdos selecionados nas diversas disciplinas concorram para desestabilizar a lógica eurocêntrica, cristã, masculina, branca e heterossexual que até agora informou o processo e para confrontá-la com outras lógicas, com outras formas de ver e entender o mundo. Todo o conhecimento escolar redefine-se, então, com base em perspectivas e identidades de grupos subalternizados, de modo a questionar visões hegemônicas e desconstruir o "olhar do poder", suas normas e seus pressupostos (McCarthy, 1998). Penso que essa abordagem pode contribuir para que um membro de um grupo oprimido entenda como se criou a situação desvantajosa em que foi colocado e como situações semelhantes, que a outros oprimem e subjugam, constituem também construções histórico-sociais, produzidas por homens e mulheres, passíveis, portanto, de serem questionadas e transformadas. A intenção é, assim, desnaturalizar os critérios usados para justificar a superioridade de certos indivíduos e grupos em relação a outros.

Não se trata, é importante tornar claro, de simplesmente substituir saberes e valores dos grupos dominantes por saberes e valores dos grupos subalternizados. Não se trata de aderir ao "enfoque Robin Hood" no currículo (McCarthy, 1998), segundo o qual se rouba de um para dar a outro. É no encontro, no atrito, entre as vozes hegemônicas e as vozes dos sujeitos oprimidos que reside a possibilidade de crítica e desconstrução das representações vigentes das relações sociais e dos grupos culturais, bem como de sua substituição por imagens e representações alternativas que expressem novas representações do mundo em que vivemos, dos grupos com que convivemos e das relações que estabelecemos. Nesse processo de crítica e de produção, a literatura em geral e outras manifestações artísticas podem oferecer significativa ajuda (McCarthy, 1998).

Mas, cabe esclarecer, não estou defendendo posições privilegiadas para determinadas disciplinas no currículo multiculturalmente orientado. Não aceito que uma ação multicultural na educação se restrinja a determinadas disciplinas ou áreas, como história, antro- 
pologia, sociologia ou estudos sociais. Se essas disciplinas podem oferecer subsídios teóricos importantes para melhor "vivermos com o outro no mundo da diferença", toda e qualquer disciplina pode cooperar com o projeto multicultural. No caso das ciências naturais, por exemplo, que supostamente "funcionam", explicando a realidade, ao abrigarem conhecimentos "universais", "transcendentes à cultura", certas questões podem orientar o desenvolvimento da abordagem que defendo. Menciono-as, apoiando-me em Harding (1996): a) em que medida as origens da ciência moderna situam-se de fato em culturas não européias?; b) existem ou podem vir a existir ciências, elaboradas em outras culturas, que também "funcionem", que também expliquem a realidade?; c) de que modo a ciência moderna pode ser considerada ocidental? Acredito que a exploração dessas questões, em um curso de ciências naturais, tanto ajuda a desafiar a suposta neutralidade cultural da ciência como a iluminar perspectivas e possibilidades insuspeitadas de desenvolvimento científico.

\section{Finalizando}

Retomo, ao finalizar, as duas grandes linhas abordadas ao longo do texto. A primeira correspondeu à análise de trabalhos sobre currículo e multiculturalismo, recentemente elaborados por autores brasileiros. Procurei identificar temáticas dominantes, abordagens metodológicas e temáticas bibliográficas. Apontei contribuições e lacunas dos estudos. Situei as influências recebidas em duas grandes tendências, uma que procura beber na fonte dos saberes produzidos nos movimentos sociais e outra que se inspira mais na produção acadêmica sobre currículo, cultura e diversidade cultural.

Para retomar a primeira linha, recorro à palavra hibridização, hoje comumente usada em estudos de fenômenos culturais contemporâneos. Concebo-a como um modo de produção cultural, um processo em que distintos discursos são mobilizados, selecionados, incorporados, misturados e traduzidos para um dado ambiente. Nesse movimento, os marcadores originais dos discursos tendem a ser esquecidos, abandonados.
As características do contexto de origem deixam de ser reconhecidas. Na nova montagem de conceitos e figuras, nas novas séries e equivalências discursivas, novos sentidos são criados.

É importante esclarecer que a multiplicidade dos discursos envolvidos na hibridização não elimina hierarquias ou binarismos, ainda que auxilie a desafiar e interromper as hierarquias estabelecidas dos discursos. Sem que se possa prever o resultado, uma nova hierarquia se cria, mais ou menos democrática que a anterior. Essa nova hierarquia deriva do reconhecimento e da sanção de alguns discursos, assim como do esquecimento e da repressão de outros (Dussel, Tiramonti e Birgin, 1998). É necessário, portanto, escolher da forma mais livre e mais igualitária que for possível os diferentes materiais que entram no caldeirão (Sarlo, 1999).

Levanto, então, a hipótese de que o processo de hibridização pelo qual se produz o conhecimento sobre multiculturalismo e currículo no Brasil pode beneficiar-se do cruzamento dinâmico das linhas que identifiquei na produção examinada. Argumento a favor das interações entre, de um lado, os conhecimentos oriundos dos movimentos sociais e das investigações que os tomam como objeto e, de outro, os conhecimentos da produção acadêmica, fundamentalmente anglo-saxônica, que começa a dominar o campo do multiculturalismo no Brasil e a influenciar, sobremaneira, a produção de nossos pesquisadores. Mesmo sem resultados garantidos, podemos empenhar-nos em uma seleção mais lúcida de teorias e práticas e procurar orientar suas traduções, reelaborações e aplicações na direção da mudança social. Mesmo que não mudemos radicalmente o mundo, podemos talvez humanizá-lo um pouco, ao desnaturalizarmos divisões, preconceitos e discriminações. Nos dias de hoje, esse aparente pouco é certamente muito.

Volto-me para a segunda linha, que se desenhou no decorrer do levantamento de questões referentes a currículo e multiculturalismo. No esforço por estimular discussões, aproximei-me de ponto que julgo crucial, em termos de ação efetiva no currículo: o processo de desconstrução, crítica, reformulação e 
hibridização dos conteúdos tradicionais, desestabilizados em vigoroso confronto com outros olhares, outras lógicas e outros pontos de vista.

Para resumir o que procurei expressar nessa parte do texto, recorro a John Willinsky (1998), cuja análise do multiculturalismo na educação me parece particularmente lúcida e provocativa. Para ele, a pergunta central que uma educação multicultural deve procurar responder é: poderemos continuar a dividir a realidade humana, como temos feito até agora, em culturas, histórias, tradições, comportamentos sexuais, sociedades e raças diferentes, e sobreviver, de modo humano, às conseqüências dessas divisões? Com o autor, penso que a resposta à pergunta demanda questionarmos, em todas as disciplinas, se essas divisões podem ser aceitas como fatos da natureza. Demanda compreendermos a construção das categorias pelas quais somos divididos, nomeados e conhecidos. Demanda darnos conta de como temos aprendido os significados das diferenças e das desigualdades que nos segregam.

Para o autor, trata-se de uma educação arriscada, capaz de afastar-nos da tranqüilidade com que nos situamos no mundo. Mas essa tranqüilidade, já há muito abalada, por diferentes crises, eventos e motivos, dissolveu-se de fato no ar, penso eu, após 11 de setembro. Se assim é, o maior risco que hoje corremos deriva não do esforço por questionar fronteiras, mas do empenho em reforçá-las, em delinear com traços mais nítidos e vigorosos as linhas que nos separam. Cabenos, então, decidir que risco preferimos, de que lado queremos ficar.

Apoiando-me em Bourdieu (2001), penso que, para melhor desnaturalizarmos, no currículo, as fronteiras que nos isolam dos outros, precisaríamos atravessar a fronteira sagrada que, de certo modo, ainda aparta o mundo acadêmico do mundo dos movimentos sociais. Talvez precisássemos sair do microcosmo acadêmico e entrar em contato com o mundo exterior, inventando um conhecimento engajado, "uma política de intervenção no mundo político que obedeça, na medida do possível, às regras em vigor no mundo científico" (p.43). A meu ver, o mundo do currículo e do multiculturalismo só teria a lucrar com essa "transgressão".
ANTÔNIO FLÁVIO BARBOSA MOREIRA doutorou-se em

Educação no Instituto de Educação da Universidade de Londres. É professor titular da Faculdade de Educação da UFRJ, onde coordena o Núcleo de Estudos de Currículo. Publicou diversos artigos sobre currículo e formação de professores, bem como o livro Currículos e Programas no Brasil (Papirus, 1990). Organizou as seguintes coletâneas: Conhecimento educacional e formação do professor (Papirus, 1994); Currículo: questões atuais (Papirus, 1997) e Currículo: políticas e práticas (Papirus, 1999). Com Tomaz Tadeu da Silva organizou Currículo, cultura e sociedade (Cortez, 1994) e Territórios contestados: o currículo e os novos mapas políticos e culturais (Vozes, 1995). Com Ana Canen organizou Ênfases e omissões no currículo (Papirus, 2001).

E-mail: afmcju@infolink.com.br

\section{Referências Bibliográficas}

APPLE, Michael W., (1999). Power, meaning and identity: essays in critical educational studies. New York: Peter Lang.

BECK, Ulrich, (2001). Terror e Estado mínimo são o Chernobyl da globalização. Folha de S. Paulo, São Paulo, 8 nov. 2001, Caderno B, p.4.

BONAMINO, Alicia C., BRANDÃO, Zaia, (1995). Currículo: tensões e alternativas. Cadernos de Pesquisa, nº 92, p.6-25.

BOURDIEU, Pierre, (1998). A máquina infernal. Folha de S. Paulo, São Paulo,12 jul. 1998, Caderno Mais!, p.7. , (2001). Contrafogos 2. Rio de Janeiro: Jorge Zahar.

CAMPOS, Rogério C., (2000). Movimentos indígenas por educação: novos sujeitos socioculturais na história recente do Brasil. Trabalho apresentado na $23^{a}$ Reunião Anual da ANPEd, Caxambu, MG

CANDAU, Vera Maria, (1997). Cotidiano escolar e cultura(s)Banco de dados- vol. I. Rio de Janeiro: CECEC - PUC/Rio.

(1999). Cotidiano escolar \& educação intercultural -

Banco de dados - vol. II. Rio de Janeiro: CECEC - PUC/Rio. (2001). Cotidiano escolar \& educação intercultural Banco de dados - vol. III. Rio de Janeiro: CECEC - PUC/Rio

CANDAU, Vera Maria, ANHORA, Carmen Teresa G., (2000). A questão didática e a perspectiva multicultural: uma articulação necessária. Trabalho apresentado na $23^{\mathrm{a}}$ Reunião Anual da ANPEd, Caxambu, MG. 
CANEN, Ana, (1997). Competência pedagógica e pluralidade cultural: eixo na formação de professores? Cadernos de Pesquisa, $\mathrm{n}^{\circ} 102$, p. 89-107.

, (1998). Educação multicultural, identidade nacional e pluralidade cultural: tensões e implicações curriculares. Trabalho apresentado na $21^{\mathrm{a}}$ Reunião Anual da ANPEd, Caxambu, MG.

, (1999). Multiculturalismo e formação docente: experiências narradas. Trabalho apresentado na $22^{\mathrm{a}}$ Reunião Anual da ANPEd, Caxambu, MG.

CANEN, Ana, ARBACHE, Ana Paula, FRANCO, Monique, (2000). Pesquisando multiculturalismo e educação: o que dizem as dissertações e teses. Trabalho apresentado na XXIII Reunião Anual da ANPEd, Caxambu, MG.

CANEN, Ana, MOREIRA, Antonio Flavio B., (2001). Reflexões sobre o multiculturalismo na escola e na formação docente. In: CANEN, A., MOREIRA, A. F. B., (orgs.). Ênfases e omissões no currículo. Campinas: Papirus.

CARLSON, Dennis, APPLE, Michael A. (2000). Teoria educacional crítica em tempos incertos. In: HYPOLITO, A. M., GANDIN, L. A., (orgs.). Educação em tempos de incertezas. Belo Horizonte: Autêntica, 2000.

CARVALHO, Marília P., VIANNA, Claúdia P., (1999). Movimentos sociais por educação: a invisibilidade dos gêneros. Cadernos de Pesquisa, n 107, p.79-96.

CÔRTES, Clélia N., (1996). A educação escolar entre os povos indígenas: da homogeneização à diversidade. Trabalho apresentado na $19^{\mathrm{a}}$ Reunião Anual da ANPEd, Caxambu, MG.

COUTINHO, José Maria, (1997). Por uma educação multicultural: uma alternativa de cidadania para o século XXI. Trabalho apresentado na 20ª Reunião Anual da ANPEd, Caxambu, MG.

CUNHA Jr., Carlos F., (1996). Homossexualidade e educação física: estereótipos, preconceitos e discriminações. Trabalho apresentado na $19^{\mathrm{a}}$ Reunião Anual da ANPEd, Caxambu, MG.

CURY, Carlos Roberto J., (1999). Direito à diferença: um reconhecimento legal. Educação em Revista, no 30, p.7-16.

DAYRELL, Juarez Tarcísio, (1996). Escola e diversidade cultural: considerações em torno da formação humana. Trabalho apresentado na $19^{\mathrm{a}}$ Reunião Anual da ANPEd, Caxambu, MG.
DEMARTINI, Zeila B. F., (2000). Relatos orais de famílias de imigrantes japoneses: elementos para a história da educação brasileira. Educação \& Sociedade, nº 72, p.43-72.

DUSSEL, Inés, TIRAMONTI, Guillermina, BIRGIN, Alejandra, (1998). Hacia uma nueva cartografía de $\mathrm{l}^{\mathrm{a}}$ reforma curricular. Reflexiones a partir de la descentralización educativa argentina. Revista de Estudios del Curriculum, v. 1, n 2, p.132161.

ELLSWORTH, Elizabeth, (1999). Multiculture in the making. In: GRANT, C. A., (ed.). Multicultural research: a reflective engagement with race, class, gender and sexual orientation. London: Falmer Press.

FERREIRA, Márcia Ondina V., (1998). Identidade étnica, condição marginal e papel da educação escolar na perspectiva dos ciganos espanhóis. Trabalho apresentado na $21^{\mathrm{a}}$ Reunião Anual da ANPEd, Caxambu, MG.

FRANCO, Alexia F., (1999). Televisão, ensino de história e pluralidade cultural: (re)pensando relações. Trabalho apresentado na $12^{\text {a }}$ Reunião Anual da ANPEd, Caxambu, MG.

GARCÍA CANCLINI, Néstor, (1990). Culturas híbridas: estrategias para entrar y salir de la modernidad. México: Grijalbo.

GIMENO SACRISTÁN, José, (1998). Poderes inestables en educación. Madrid: Morata.

GOMES, Ana Maria R., (1999). Crianças ciganas e a escola italiana: breve relato etnográfico. Trabalho apresentado na $22^{\mathrm{a}}$ Reunião Anual da ANPEd, Caxambu, MG.

GOMES, Ana Maria R., (2000). Produção e reprodução da cultura escolar: algumas delimitações para a análise da experiência dos professores indígenas Xakriabá. Educação em Revista, número especial, p. 37-68.

GOMES, Nilma L., (1996). Os jovens rappers e a escola: a construção da resistência. Trabalho apresentado na $19^{\mathrm{a}}$ Reunião Anual da ANPEd, Caxambu, MG.

GOMES, Nilma L., (1997). Educação em Belo Horizonte: um movimento aberto à comunidade? Educação em Revista, nº $26, \mathrm{p}$. $39-54$.

GOMES, Nilma L., (2000). Diversidade cultural e formação de professores: um diálogo necessário. Educação em Revista, número especial, p.151-167. 
GONÇALVES, Luiz Alberto O., SILVA, Petronilha B. G., (1998). O jogo das diferenças: o multiculturalismo e seus contextos. Belo Horizonte: Autêntica.

HAGE, Salomão M., (1996). Construindo uma escola que interessa às classes populares: análise da proposta político-pedagógica da Escola Cidade de Emaús. Trabalho apresentado na $19^{\mathrm{a}}$ Reunião Anual da ANPEd, Caxambu, MG.

HARDING, Sandra, (1996). Is Science multicultural? Challenges, resources, opportunities, uncertainties. In: GOLDBERG, D. T., (ed.). Multiculturalism: a critical reader. Oxford: Blackwell.

KINCHELOE, Joe L., STEINBERG, Shirley R., (1997). Changing multiculturalism. Buckingham: Open University Press.

KRAMER, Sonia, (1995). Questões raciais e educação: entre lembranças e reflexões. Cadernos de Pesquisa, n 93, p.66-71.

KREUTZ, Lúcio, (1999). Identidade étnica e processo escolar. Cadernos de Pesquisa, $\mathrm{n}^{\circ}$ 107, p.79-96.

KREUTZ, Lúcio, (2000). Escolas comunitárias de imigrantes no Brasil: instâncias de coordenação e estruturas de apoio. Revista Brasileira de Educação, n $^{\circ}$ 15, p. 159-176

LOPES, Alice R. C., (1997). Pluralismo cultural e políticas de currículo nacional. Trabalho apresentado na $20^{\mathrm{a}}$ Reunião Anual da ANPEd, Caxambu, MG.

MARANHÃO, Helena P., (2000). A diversidade e seus sentidos nos Parâmetros Curriculares Nacionais ( $5^{a}$ a $8^{a}$ séries do ensino fundamental): questões prévias. Trabalho apresentado na $23^{\mathrm{a}}$ Reunião Anual da ANPEd, Caxambu, MG.

MCCARTHY, Cameron, (1988). Rethinking liberal and radical perspectives on racial inequality in schooling: making the case for nonsynchrony. Harvard Educational Review, v. 58, $\mathrm{n}^{\mathrm{o}} 3$, p.265-279.

MCCARTHY, Cameron, (1998). The uses of culture: education and the limits of ethnic affiliation. New York: Routledge.

MCLAREN, Peter, (1997). Multiculturalismo crítico. São Paulo: Cortez.

MEYER, Dagmar E. E., (2000). “Alemão”, “estrangeiro” ou "teuto-brasileiro"? Representações de docência teuto-brasileiro-evangélica no Rio Grande do Sul. Trabalho apresentado na $23^{\mathrm{a}}$ Reunião Anual da ANPEd, Caxambu, MG.
MONTE, Nieta L., (2000). E agora, cara pálida? Educação e povos indígenas 500 anos depois. Revista Brasileira de Educação, ${ }^{\circ}$ 15 , p.118-133.

OLIVEIRA, Renato José, CANEN, Ana, FRANCO, Monique, (2000). Ética, multiculturalismo e educação: articulação possível? Revista Brasileira de Educação, ${ }^{\circ}$ 13, p.113-126.

OLIVEN, Anabela C., (1996). Multiculturalismo e a política de ingresso nas universidades dos EUA. Educação \& Realidade, v. $21, n^{\circ} 2$, p. $74-87$.

PARAÍSO, Marlucy, (1995). Gênero na formação do/a professor/ $a$ : campo de silêncio do currículo? Trabalho apresentado na $18^{\mathrm{a}}$ Reunião Anual da ANPEd, Caxambu, MG.

PARAÍSO, Marlucy, (1997). Currículo, etnia e poder: o silêncio que discrimina. Trabalho apresentado na $20^{\mathrm{a}}$ Reunião Anual da ANPEd, Caxambu, MG

PARAÍSO, Marlucy, (1998). Currículo e identidades: a produção de gênero, sexualidade e etnia na formação da professora. Trabalho apresentado na $21^{\text {a }}$ Reunião Anual da ANPEd, Caxambu, MG.

PIMENTA, Selma G., (2000). A pesquisa em didática - 1996 a 1999. In: CANDAU, V. M., (org.). Didática, currículo e saberes escolares. Rio de Janeiro: DP\&A

PINTO, Regina P., (1999). Diferenças étnico-raciais e a formação do professor. Cadernos de Pesquisa, n 108 , p.199-231.

SANTANA, Patrícia Maria S., (2000). Os professores negros como atores sociais em escolas da rede municipal de ensino de Belo Horizonte. Educação em Revista, número especial, p.187- 207.

SANTOS, Lucíola L. C. P., LOPES, José S. M., (1997). Globalização, multiculturalismo e currículo. In: MOREIRA, A. F. B., (org.). Currículo: questões atuais. Campinas: Papirus.

SANTOS, Luís Henrique S., (1997). "Um preto mais clarinho..." ou dos discursos que se dobram nos corpos produzindo o que somos. Educação e Realidade, v. 22, nº 2, p.81-115.

SARLO, Beatriz, (1999). Escenas de la vida posmoderna: intelectuales, arte y videocultura en la Argentina. Buenos Aires: Ariel.

SILVA, Ana Célia, (1999). As transformações da representação social do negro no livro didático e seus determinantes. Trabalho apresentado na $22^{\mathrm{a}}$ Reunião Anual da ANPED, Caxambu, MG. 
SILVA, Rosa Helena D., (1999). Balanço dos movimentos dos povos indígenas no Brasil e a questão educativa. Trabalho apresentado na 22 ${ }^{\mathrm{a}}$ Reunião Anual da ANPEd, Caxambu, MG.

SILVA, Tomaz Tadeu, (1999). Documentos de identidade: uma introdução às teorias de currículo. Belo Horizonte: Autêntica.

SILVEIRA, Marly, (1999). Pluralidade cultural ou atualidade do mito da democracia racial? Trabalho apresentado na $22^{\mathrm{a}}$ Reunião Anual da ANPEd, Caxambu, MG.

SOUSA SANTOS, Boaventura, (1997). Toward a multicultural conception of human rights. Zeitschrift für Rechtssoziologie, $\mathrm{n}^{\mathrm{o}} 18, \mathrm{p} .1-14$.

SOUZA, Jane F., (1999). Gênero e sexualidade nas pedagogias culturais: implicações para a educação infantil. Trabalho apresentado na $22^{\mathrm{a}}$ Reunião Anual da ANPEd, Caxambu, MG.

SOUZA, Maria Elena V., (1997). O movimento negro no Rio de Janeiro e a educação escolar. Trabalho apresentado na $20^{\mathrm{a}}$ Reunião Anual da ANPED, Caxambu, MG.
STOER, Stephen R., CORTESÃO, Luiza, (1999). Levantando a pedra: da pedagogia inter/multicultural às políticas educativas numa época de transnacionalização. Porto: Afrontamento.

VALENTE, Ana Lúcia E. F., (1995). Proposta metodológica de combate ao racismo nas escolas. Cadernos de Pesquisa, n 93, p.40-50. , (1996). Quando as diferenças são um problema. Trabalho apresentado na $19^{a}$ Reunião Anual da ANPED, Caxambu, MG.

VALENTE, Ana Lúcia E. F., (1998). Estado, educação e etnicidade: a experiência belga. Cadernos de Pesquisa, nº 105, p.135-159.

WELLER, Wivian, (1995). Educação intercultural e a dificuldade de sua prática: um estudo da imagem do imigrante e sua família em livros didáticos. Educação \& Sociedade, nº 52, p.432-445.

WILLINSKY, John, (1998). The educational politics of identity and category. Interchange, v. 29, $\mathrm{n}^{\circ} 4$, p.385-402. 
To create the non-state public or to make the state public?

The forms of distribution of resources and responsibilities with respect to educational policy are at present diversified. The scope of traditional state action has been the object of forceful appeals and policies of expressive encouragement to community participation, particularly in less economically developed countries. These find expression in programmes aimed at extending access to schooling to populations who until that time have been denied such benefits and emphasise alterations in management style based on community participation. Such programmes change the trajectory of expansion followed by school systems world-wide with regard to the conception of what constitutes essentially state activity. Based on this sociological reflection, the text discusses the arguments that sustain such types of programme which are taken to be more democratic and inclusive.

Regina Leite Garcia

\section{A busca da coerência: reflexões so- bre a produção do GT Educação Po- pular}

O texto problematiza as questões recorrentes na produção do GT Educação Popular: amorosidade, autopoiesis, processo de auto-eco-organização; nova organização a partir do caos - o tempo/relógio e o tempo/interesse coletivo; em defesa dos homens lentos; uma sociologia da história lenta; a relação prática/ teoria/prática; a reflexão epistemológica sobre quem, como, e onde é produzido o conhecimento; a segunda ruptura epistemológica que reaproxima a ciência e o senso comum; a dimensão auto-reflexiva da questão epistemológica; a chegada do estranho nas pesquisas em educação popular; a dúvida que leva ao novo: a crise da compreensão é nossa; os que não vêem porque não compreendem; a aceitação do outro como condição para a aceitação de si mesmo; compreender o compreender; a reescrita da história a partir do ponto de vista dos subalternos; narrativas perdidas na história oficial; o discurso oral; a hegemonia de uma lógica que silencia as lógicas do cotidiano; a religiosidade popular - responsabilidade compartilhada; solidariedade de preocupações. E o desafio que fica é: se o GT Educação Popular repudia a hierarquização dos saberes como formas de exercício de poder, se reconhece formas plurais de cultura resultado de visões de mundo que carregam diferentes lógicas, como passam os seus componentes a tecer o currículo em suas ações pedagógicas, seja dentro seja fora da escola, melhor dizendo, em que mudam suas ações político-pedagógicas?

\section{In the search for coherence: reflections on the production of the Working Group on Popular Education}

This texts sets out to problematise recurrent questions in the production of the Working Group on Popular Education: amorosity, 'autopoiesis', process of auto-eco-organisation; new organisation based on chaos - timel clock and time/collective interest; in defence of slow men; a sociology of slow history - the relation practicel theory/practice; the epistemological reflection on who, how and where knowledge is produced; the second epistemological rupture which brings science and common sense closer together again; the auto-reflexive dimension of the epistemological question - the arrival of outsiders in research in popular education - the doubt which leads to the discovery of the new - the crisis of understanding is ours - those who do not see because they do not understand; the acceptance of the other as a condition for self-acceptance; understanding understanding - rewriting history from the point of view of the subordinate; narratives lost in official history; oral discourse; the hegemony of a logic which silences the logics of daily life; popular religiosity - shared responsibility; solidarity of concerns. And the challenge which remains is if the Working Group on Popular Education repudiates the ranking of knowledge as a means of exercising power, if it recognises plural forms of culture giving rise to visions of the world which contain different logics, how do the group members begin to construct a curriculum in their pedagogical actions, either inside or outside the school, or rather, how do their political-pedagogical practices change?

Antônio Flávio Barbosa Moreira

A recente produção científica sobre currículo e multiculturalismo no Brasil (1995-2000): avanços, desafios e tensões

$\mathrm{O}$ artigo analisa a recente produção científica brasileira sobre currículo e multiculturalismo. Foram incluídos nessa produção os artigos publicados nos seguintes periódicos: Cadernos de Pesquisa, Revista Brasileira de Educação, Educação \& Realidade, Educação \& Sociedade e Educação em Revista, bem como os trabalhos apresentados nas Reuniões Anuais da ANPEd. O período focalizado foi de 1995 a 2000. Procurou-se identificar as temáticas abordadas, os principais pontos de vista defendidos, as influências teóricas mais significativas, os enfoques metodológicos, as contribuições e as lacunas. Discutiram-se, também, tensões e desafios observados na produção em pauta. Insistiu-se na importância do diálogo entre os autores 
mais ligados aos movimentos sociais, que recorrem dominantemente à teoria social e à antropologia e os autores mais ligados a questões pedagógicas, que tendem a se apoiar na teorização de currículo, na teoria crítica, nos estudos culturais e no pensamento pósmoderno e pós-estrutural.

\section{Recent scientific production on} curriculum and multiculturalism in Brazil (1995-2000): advances, challenges and tensions

This article presents an analysis of recent Brazilian scientific production on curriculum and multiculturalism. It examines articles published between 1995 and 2000 in the following journals: Cadernos de Pesquisa, Revista Brasileira de Educação, Educação \& Realidade, Educação \& Sociedade e Educação em Revista. It also focuses on papers presented at the Annual Meetings of ANPEd during the same period. The study aims at identifying the main themes and arguments, the most significant theoretical influences, the methodological procedures employed, the contributions and the gaps. The tensions and challenges observed in the articles are also discussed. The paper insists on the importance of a dialogue between those authors more closely associated with social movements who are chiefly influenced by social theory and anthropology and those authors more closely associated with curriculum and pedagogy who are influenced by critical theory, cultural studies, post-modernism and post-structuralism.

Iria Brzezinski e Elsa Garrido

Análise dos trabalhos do GT Formação de Professores: o que revelam as pesquisas do período 1992-1998

O texto analisa setenta trabalhos apresentados no GT Formação de Profes- sores da ANPEd, no período19921998. As pesquisas foram organizadas segundo cinco descritores: formação inicial de professores, formação continuada, práticas pedagógicas, profissionalização docente e revisão da literatura sobre formação de professores. $\mathrm{O}$ estudo procura oferecer uma visão compreensiva sobre as questões, os referenciais teóricos e os avanços do conhecimento na área, explorando relações, explicitando divergências e delineando tendências de pesquisa. $\mathrm{O}$ conjunto dos trabalhos traz contribuições para fundamentar e subsidiar propostas e políticas de formação e de desenvolvimento profissional docente.

\section{Papers presented in the Working Group on Teacher Formation - what the research in the period 1992-1998 reveals}

This texts sets out to analyse seventy papers presented in the ANPEd Working Group on Teacher Formation during the period 1992-1998. The research was organised employing five categories: initial teacher formation, continued formation, pedagogical practices, teacher professionalisation and literature review on teacher formation. The study seeks to offer a comprehensive vision with regard to theoretical frameworks and recent advances in the area, exploring relations, expressing divergences and outlining research tendencies. The set of papers offers contributions to substantiate proposals and policies for teacher formation and professional development.

\section{Maria Rita Neto Sales Oliveira}

Do mito da tecnologia ao paradigma tecnológico; a mediação tecnológica nas práticas didático-pedagógicas O objetivo principal do texto é apresentar uma visão crítica da tecnologia no âmbito da educação e do ensino.
Aborda três hipóteses sobre a matéria: tecnologia educacional revisitada, modelo da competência e mito da tecnologia, evidenciando seus problemas, reducionismos e limites. Em sequiência, discute as características do novo paradigma tecnológico, e alguns aspectos do Livro verde do Ministério da Ciência e Tecnologia do país. Como conclusão, levanta algumas implicações da necessária superação dos problemas apontados, para o entendimento e tratamento crítico das tecnologias nas práticas didático-pedagógicas.

From the myth of technology to the technological paradigm: technological mediation in pedagogical practices The main objective of the text is to present a critical perspective on technology in education and teaching. Three hypotheses are discussed: educational technology revisited, the competence model and the myth of technology. The text also discusses the characteristics of the new technological paradigm and some aspects of The green book published by the brazilian Ministry of Science and Technology. In conclusion, the article points to some of the implications linked to a critical understanding and treatment of technology in teaching and educational practice.

Bernardete Angelina Gatti

Reflexão sobre os desafios da pósgraduação: novas perspectivas sociais, conhecimento e poder $\mathrm{O}$ artigo salienta as diferenças entre o momento histórico em que os programas de mestrado e doutorado foram criados e o momento atual. Discute-se o papel social desses cursos na dicotomia conhecimento $x$ poder e o dilema a ser enfrentado por mestrados e doutorados que vêm sendo instados, pela sociedade, a abrir-se a novas modali- 